\title{
Correction to: Clinical features, radiological profiles, and surgical outcomes of primary intracranial solitary plasmacytomas: a report of 17 cases and a pooled analysis of individual patient data
}

\author{
Xiu-Jian $\mathrm{Ma}^{1} \cdot \mathrm{Da} \mathrm{Li}^{1} \cdot$ Liang Wang $^{1} \cdot$ Shu-Yu Hao ${ }^{1} \cdot$ Li-Wei Zhang $^{1} \cdot$ Jun-Ting Zhang ${ }^{1} \cdot$ Zhen Wu$^{1}(\mathbb{0}$ \\ Published online: 25 January 2019 \\ ○) Springer Science+Business Media, LLC, part of Springer Nature 2019
}

\section{Correction to: Journal of Neuro-Oncology https://doi.org/10.1007/s11060-019-03089-z}

The article Clinical features, radiological profiles, and surgical outcomes of primary intracranial solitary plasmacytomas: a report of 17 cases and a pooled analysis of individual patient data, written by Xiu-Jian Ma, Da Li, Liang Wang, Shu-Yu Hao, Li-Wei Zhang, Jun-Ting Zhang, Zhen Wu, was originally published electronically on the publisher's internet portal (currently SpringerLink) on 7 January 2019 with open access.

With the authors' decision to step back from Open Choice, the copyright of the article changed on 25 January
2019 to $\odot$ Springer Science + Business Media, LLC, part of Springer Nature 2019 and the article is forthwith distributed under the terms of copyright.

The original article can be found online at https://doi.org/10.1007/ s11060-019-03089-z.

Zhen Wu

wz_ttyy@163.com

1 Department of Neurosurgery, Beijing Tiantan Hospital,

Capital Medical University, Tiantan Xili 6, Dongcheng

District, Beijing, People's Republic of China 